\title{
Piezoelectric Thin Films
}

\author{
Tadashi SHIOSAKI \\ Department of Electronics, Faculty of Engineering, Kyoto University, Sakyo-ku, Kyoto-shi 606, Japan
}

\section{圧 電 体 薄 膜 \\ 塩菩 忠}

京都大学工学部電子工学科, 606 京都市左京区吉田本町

\begin{abstract}
圧電薄膜材料とその製造法並びに応用の発展をふり返って述べる. 圧電薄膜材料は非強誘電体あるいは強誘電体 の硫化物, 酸化物, 窒化物が主である. 圧電薄膜の実用化にはエピタキシャル薄膜あるいは自発分極軸が配向し た薄膜が必要である.最も広く用いられている圧電薄膜材料は自発分極軸が配向した ZnO 薄膜である. ガラス 基板上の自発分極軸が配向した $\mathrm{ZnO}$ 薄膜を用いたテレビジョン中間周波用の表面波フィルタは1991年の初頭現 在で月産3,700,000個生産されている.
\end{abstract}

[Received June 7, 1991]

\begin{abstract}
The history of the developments in materials, fabrication methods and applications of piezoelectric thin films are reviewed. The materials for the piezoelectric thin films are non-ferroelectric and ferroelectric sulfides, oxides and nitrides. Epitaxial films and polar axis oriented films are useful for the practical applications of piezoelectric thin films. The most widely used piezoelectric thin film material is the polar axis oriented $\mathrm{ZnO}$ thin film. The surface acoustic wave filters for TV-IF filters made of the polar axis oriented $\mathrm{ZnO}$ thin films on glass substrates are produced at the production rates of several million pieces per month in 1991.
\end{abstract}

Key-words : Piezoelectric films, ZnO, AlN, Ferroelectric films

\section{Introduction}

INCE the first report on evaporated CdS films for Uuse as VHF and UHF bulk acoustic wave transducers in 1963,1),2) a number of investigations on piezoelectric thin films have been carried out.

In the material research, $\mathrm{ZnO}$ had been recognized as being the most promising thin film piezoelectric material for VHF and UHF acoustic applications due mainly to its fairly large coupling coefficient, ${ }^{3)}$ and it was reported in December, 1965 that its piezoelectric thin film can be grown by reactive sputtering of zinc in oxygen. ${ }^{4)}$,5) Ever since the $\mathrm{ZnO}$ film has been regarded as the most useful piezoelectric thin film. Piezoelectric AIN thin film acoustic transducers made by evaporation of $\mathrm{Al}$ in $\mathrm{N}_{2}$ or $\mathrm{NH}_{3}$ atmosphere onto metal films on sapphire rods at substrate temperatures of $300^{\circ}-1200^{\circ} \mathrm{C}$ were reported in October, 1968.6) The piezoelectric film of $\mathrm{LiNbO}_{3}$ grown by dc triode sputtering on gold plated fused quartz and sapphire at substrate temperatures of $325^{\circ}-380^{\circ} \mathrm{C}$ was reported in January 1969. ${ }^{7)}$ Selenium films evaporated epitaxially on tellurium was also reported as piezoelectric high and low frequency transducers in
March 1969.8) Thin piezoelectric films of $\mathrm{Bi}_{12} \mathrm{PbO}_{19}$, $\mathrm{K}_{3} \mathrm{Li}_{2} \mathrm{Nb}_{5} \mathrm{O}_{15}, \mathrm{PbTiO}_{3}$, and $\mathrm{PZT}$ films have been also reported.9)-20) Recently piezoelectric $\mathrm{Li}_{2} \mathrm{~B}_{4} \mathrm{O}_{7}$ and $\mathrm{Ta}_{2} \mathrm{O}_{5}$ films have been also sputter deposited. ${ }^{21)-23)}$

Piezoelectric thin films were first used as VHF and UHF bulk wave transducers for physical acoustics and delay line application. Then piezoelectric thin evaporated Se films for low frequency transducers for composite resonators were reported in June 1970 , and a more practical proposal to use sputtered $\mathrm{ZnO}$ films at the low frequency range from audio frequency to $100 \mathrm{kHz}$ was made in $1974 .^{24), 25)}$ Also in September 1970, the first definitive surface wave transducer studies using sputtered $\mathrm{ZnO}$ films were reported.

The importance of thin piezoelectric films is due mainly to that only a thin piezoelectric layer with a small area is needed in many kinds of applications, and that better electromechanical properties such as a higher frequency response, a higher coupling coefficient and a smaller temperature coefficient of frequency may be attained by using the composites of thin piezoelectric films and other materials which are used as bulk wave propagation media, surface wave propagation substrates and mechanical resonators. Figure 1 shows operation modes of devices which use piezoelectric thin film transducers. In any of these modes the piezoelectric film occupies a thin and small area. Therefore material cost for piezoelectricity may be small, and suitable counterpart materials as bulk wave media, surface wave substrates, and mechanical resonators can be chosen from view points of frequency, loss, temperature coefficients of frequency, ease of fabrication, cost, etc.. In addition, it is also a very advantageous that thin film piezoelectric transducers can be integrated on $\mathrm{Si}$ and other electrical and optical devices by fabrication techniques compatible with the industrial Si process.

The main techniques to fabricate oxide and nitride 
(a)

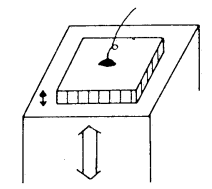

(c)

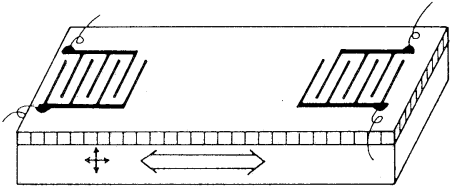

(d)

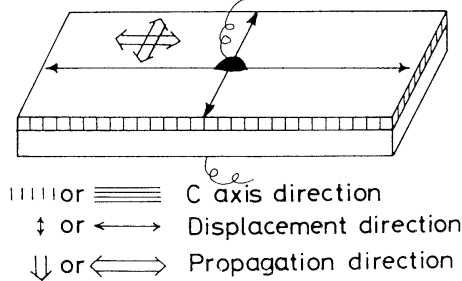

Fig. 1. The operation modes of piezoelectric films.

piezoelectric films are thermal evaporation, sputtering, ion plating, chemical vapor deposition, and solgel coating/sintering.

\section{2. $\mathrm{ZnO}$ films}

\subsection{Piezoelectricity of $\mathrm{ZnO}$ film}

The single crystal of $\mathrm{ZnO}$ belongs to the point group $6 \mathrm{~mm}$ (wurtzite) and its $c$-axis is the crystallographic polar axis. Because of this crystallographic symmetry if the $c$-axis of all polycrystallites which compose an ideal polycrystalline $\mathrm{ZnO}$ film are in one direction and their crystallographic polarity is the same then even if their $a$-axis is at random, the $\mathrm{ZnO}$ film has the same elastic, piezoelectric, dielectric and other crystallographic and lattice properties as those of the single crystal $\mathrm{ZnO}$. Physical properties of real $c$-axis oriented polycrystalline $\mathrm{ZnO}$ films are also very similar to those of the single crystal $\mathrm{ZnO}$ except for such properties as transport phenomena related carrier concentration, impurity, grain boundary and surface states.

The II-VI and III-V compounds with the wurtzite structure to which $\mathrm{ZnO}$, CdS and AlN belong have a very natural tendency to grow with their $c$-axis perpendicular to the surface of non-singlecrystalline materials and also grow epitaxially onto the surface of suitable single crystal substrates. In the former the $a$-axis orientation is usually completely at random and the film is called " $c$-axis oriented film". The $a$-axis orientation of the latter is definite and the film is called the "epitaxial film". As far as piezoelectricty is concerned the " $c$-axis oriented film" with the uniform polarity as is the case in most films, is good enough. The epitaxial film maybe become more important at higher frequencies.

It has been known Sezawa mode propagating in the $\mathrm{ZnO}$ film epitaxially sputter-deposited on the $R(10 \overline{1} 2)$ plane sapphire substrate gives a high velocity and a high coupling.
Table 1. Sputtering conditions of good quality $\mathrm{ZnO}$ films by a planar magnetron sputtering system ANELVA SPF $200 \mathrm{H}$.

$$
\begin{array}{ll}
\text { Atmospheric gas } & \mathrm{O}_{2}+\mathrm{Ar}(1: 1) \\
\text { Gas pressure } & 3 \times 10^{-3}-3 \times 10^{-2} \text { Torr } \\
\text { Target } & \text { ZnO ceramics, Zn metal } \\
\text { Target size } & 100 \mathrm{~mm} \text { diam. } 6 \mathrm{~mm} \text { thick } \\
\text { Target-substrate } & 40 \mathrm{~mm} \\
\text { spacing } & 50-400 \mathrm{~W} \\
\text { Rf input } & 0.8-48 \mu \mathrm{m} \\
\text { Film thickness } & \text { maximum } 9.8 \mu \mathrm{m} / \mathrm{h} \\
\text { Deposition rate } & \text { glass, Si, metal, metal film, } \\
\text { Substrate } & \text { sapphire, metalized polymer }
\end{array}
$$

\subsection{Fabrication of piezoelectric $\mathrm{ZnO}$ films}

There are many kinds of fabrication techniques to deposit the $c$-axis oriented $\mathrm{ZnO}$ film, among which magnetron sputtering deposition methods are considered to be the best due to their reproducibility of quality and yield of the practical films and also due to its mass-productivity. There are also many kinds of magnetron sputtering systems. The author and his colleagues studied the growth of the high quality piezoelectric $\mathrm{ZnO}$ films by using a magnetron sputtering system ANELVA SPF-200H. Sputtering conditions of piezoelectric $\mathrm{ZnO}$ films are shown in Table $1.26), 27)$

\section{Other piezoelectric films}

\subsection{AIN}

The AlN film has been also studied along with the $\mathrm{ZnO}$ film due to its higher ultrasonic velocity, higher electrical resistance and lower film growth temperature. The polar axis oriented AlN films can be grown on various kinds of substrates even at room temperature by magnetron sputtering. ${ }^{28)}$ The epitaxial films of AlN can be grown on sapphire and silicon single crystal substrates. ${ }^{29)}$ There have been a lot of works on the composite resonators which use the $\mathrm{ZnO}$ or AlN films and $\mathrm{SiO}_{2}$ or $\mathrm{p}^{++} \mathrm{Si}$ membranes fabricated by a chemical anisotropic etching or other method of $\mathrm{Si}$ and $\mathrm{GaAs.}{ }^{30)-35)}$ The studies for higher overtone bulk acoustic resonators and polar axis tilting shear wave transducers have been also made. ${ }^{36)}, 37$ )

3.2 $\mathrm{LiNbO}_{3}, \quad \mathrm{~K}_{3} \mathrm{Li}_{2} \mathrm{Nb}_{5} \mathrm{O}_{15}, \mathrm{PbTiO}_{3}, \mathrm{PZT}$ and other ferroelectrics

Piezoelectric thin $\mathrm{LiNbO}_{3}$ film was first prepared by triode sputtering at substrate temperatures of $325^{\circ}-380^{\circ} \mathrm{C}$, though the crystallographic orientation is not so good as those of $\mathrm{ZnO}$ and $\mathrm{AlN}$ films. The measured dielectric constant was 65 , and the piezoelectric coupling coefficient $k_{\mathrm{t}}$ was 0.08 which is about half of 0.17 the single crystal value for the thickness longitudinal mode in the $z$ direction. ${ }^{7}$ )

Surface acoustic waves were exited and detected with IDT's on top of the highly (001) oriented $\mathrm{K}_{3} \mathrm{Li}_{2}$ 
$\mathrm{Nb}_{5} \mathrm{O}_{15}$ film on (0112) sapphire. The highly (001) oriented $\mathrm{K}_{3} \mathrm{Li}_{2} \mathrm{Nb}_{5} \mathrm{O}_{15}$ films were grown on (0112) sapphire substrates in the sputtering condition of an $\operatorname{Ar}(50 \%)+\mathrm{O}_{2}(50 \%)$ gas pressure of $9.0 \times 10^{-2}$ Torr, an rf input power of $120 \mathrm{~W}$, and a substrate temperature of $520^{\circ} \mathrm{C}$ by rf diode sputtering of a 4 inch diameter ceramic target. ${ }^{10)}$

An epitaxial $\mathrm{PbTiO}_{3}$ film was formed on a patterned $\mathrm{Pt}$ electrode film embedded on a $\mathrm{SrTiO}_{3}$ single crystal by a seeded lateral growth, and the electromechanical coupling coefficient $k_{\mathrm{t}}$ of the $\mathrm{PbTiO}_{3}$ film is as large as 0.8.38) The piezoelectricity of sputter deposited $\mathrm{PbTiO}_{3}$ and $\mathrm{PZT}$ films were also reported. ${ }^{39), 40)}$

\section{$3.3 \mathrm{Bi}_{12} \mathrm{PbO}_{19}$}

Thin piezoelectric film of $\mathrm{Bi}_{12} \mathrm{PbO}_{19}$, which belongs to the $\gamma-\mathrm{Bi}_{2} \mathrm{O}_{3}$ family, was grown by sputtering at the substrate temperatures of $100^{\circ}-600^{\circ} \mathrm{C}$. The crystallographic axis is highly oriented and gives longitudinal bulk wave velocity of $3600-3800 \mathrm{~m} / \mathrm{s}$. The electromechanical coupling coefficient for the longitudinal thickness mode is $\left.0.16-0.22 .{ }^{9}\right)$

$3.4 \quad \mathrm{Ta}_{2} \mathrm{O}_{5}$

A Ta $\mathrm{O}_{5}$ thin film whose $x$ axis is oriented perpendicularly to the substrate face can be fabricated by the planar magnetron type reactive dc-diode sputtering and the $x$ axis oriented $\mathrm{Ta}_{2} \mathrm{O}_{5}$ thin film gives rise to piezoelectric properties. ${ }^{21), 22)}$ The crystal symmetry of the $\mathrm{Ta}_{2} \mathrm{O}_{5}$ crystal is monoclinic. The monoclinic film with m symmetry whose $x$ axis is oriented and $y$ and $z$ axes are random in $x$ plane shows the similar properties as the crystals of $6 \mathrm{~mm}$ symmetry as $\mathrm{ZnO}$ and the piezoelectric ceramics of $\infty \mathrm{mm}$ symmetry, by exchanging the notation of the $x$ axis and the $z$ axis.

\section{$3.5 \mathrm{Li}_{2} \mathrm{~B}_{4} \mathrm{O}_{7}$}

A highly polar-axis oriented film of $\mathrm{Li}_{2} \mathrm{~B}_{4} \mathrm{O}_{7}$ have been grown by a vapor deposition method under a low gas pressure. The piezoelectric voltage responses at applying and releasing a static pressure perpendicular to the film surface of the $\mathrm{Li}_{2} \mathrm{~B}_{4} \mathrm{O}_{7}$ film have been higher than the $\mathrm{RF}$ sputter deposited $\mathrm{ZnO}$ film. ${ }^{23)}$

\section{Applications}

\subsection{High frequency applications}

(a) Delay lines

At microwave frequencies higher than $1 \mathrm{GHz}$, bulk acoustic wave delay lines show better characteristics than surface acoustic wave delay lines. Piezoelectric $\mathrm{ZnO}$ thin films deposited on the bottom electrodes on both sides of singlecrystal substrate such as sapphire and YAG with low acoustic propagation losses are used as transducers. The size and weight of the acoustic delay line is by orders of magnitudes smaller than those of the coaxial cable delay line. 41$)$

(b) Acoustic microscope

The principle of the acoustic microscope is shown

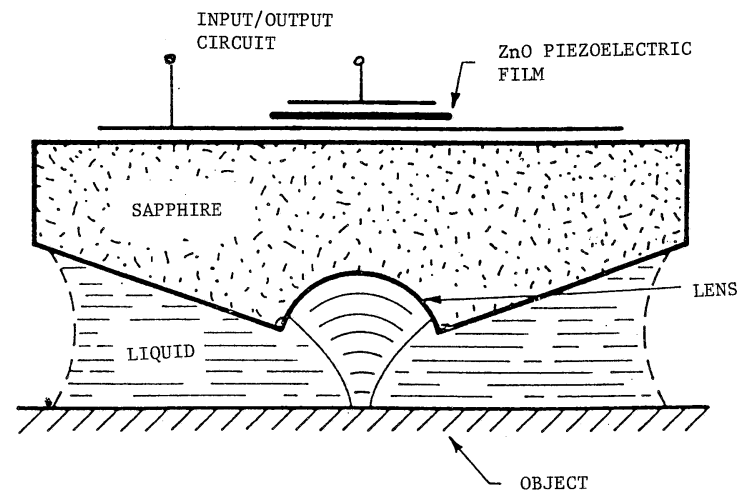

Fig. 2. The schematic diagram to show the principle of the acoustic microscope.

in Fig. 2. Electromagnetic waves at VHF and UHF frequencies are transduced to the acoustic waves, which are focused with an acoustic lens. The lens can be spherical or cylindrical. The acoustic reflectance at the focal point or line is measured. By scanning the surface of the object with the point or line focused acoustic beam an image is obtained as in SEM micrograph. Transmission type acoustic microscopes are also available. Not only the top surface but also the under surface and bottom surface can be viewed by acoustic microscopes. The acoustic microscopes which can measure the surface acoustic wave velocity of the object have been also developed. ${ }^{42)}$

(c) Composite resonator

There have been a lot of works on the composite resonators which use the $\mathrm{ZnO}$ or AlN films and $\mathrm{SiO}_{2}$ or $\mathrm{p}^{++} \mathrm{Si}$ membrane fabricated by a chemical anisotropic etching or other methods of $\mathrm{Si}$ and $\mathrm{GaAs}$ as mentioned above. ${ }^{30-37)}$ The studies for higher overtone bulk acoustic resonators and $c$-axis tilting shear wave transducers have been also continued. The advantage of these composite resonators with $\mathrm{Si}$ is the possibility to integrate the electrical integrated circuits and the micro electromechanical resonators on one chip.

\section{(d) PAS transducers}

Piezoelectric $\mathrm{ZnO}$ thin film transducers have been used for the photo acoustic microscopy (PAS) of semiconductors as GaAs and CdS.

\subsection{Low frequency applications}

(a) Composite tuning fork resonator

Tuning fork filters were fabricated by sputter depositing piezoelectric $\mathrm{ZnO}$ thin films on the side walls of micro tuning forks made of the invariant elastic Elinvar alloy as shown in Fig. 3. The temperature dependence of the resonant frequency of the composite tuning fork resonator can be adjusted by heat treating the Elinvar alloy giving rise to a almost linear dependence with a negative, zero or positive temperature coefficient of frequency. The temperature dependence of frequency of a $\mathrm{ZnO} /$ Elinvar resonator for a watch oscillator is shown in Fig. 4 which is an example of the application of a small tempera- 


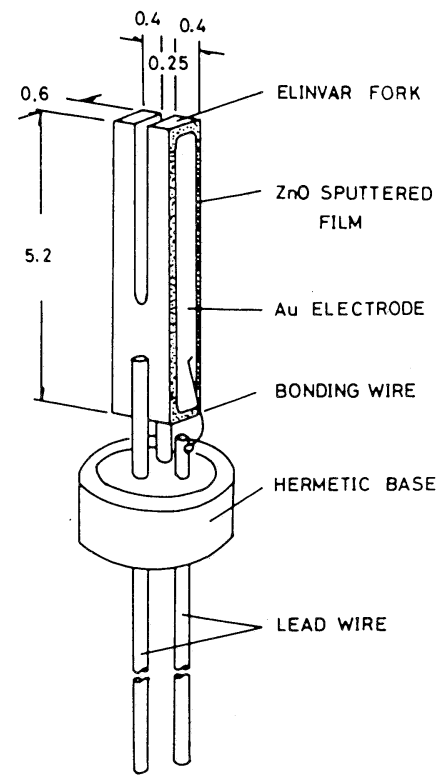

Fig. 3. The composite tuning fork made of a $\mathrm{ZnO}$ film and Elinvar alloy.

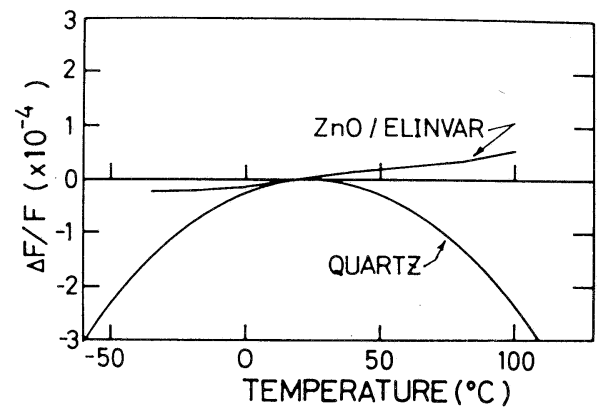

Fig. 4. The temperature dependence of frequency of a $\mathrm{ZnO} / \mathrm{Elin}$ var resonator.

ture coefficient. ${ }^{26)}$ On the contrary, the tempeature coefficient of frequency of the $\mathrm{ZnO} /$ Elinvar composite can be even larger to $0.02 \% /{ }^{\circ} \mathrm{C}$ by the heat treatment, and then a kind of temperature sensor can be given by detecting the oscillation frequency. ${ }^{28)}$

(b) Engine knocking sensor

The composite of a piezoelectric $\mathrm{ZnO}$ thin film and Elinvar alloy has a high fracture toughness and is suitable to a sensor to detect a strong vibration. The Elinvar base has a high machinability and the sensor with an appropriate shape and size can be fastened firmly by means of a screw. ${ }^{28)}$

(c) Si diaphgram accelerometer

The composite of a piezoelectric thin film and a cantilever beam made by an anisotropic or other etching can detect the acceleration. The output voltage is amplified with an FET incorporated on the same $\mathrm{Si}$ substrate.

(d) Audio devices

Piezoelectric thin films of $\mathrm{ZnO}$ and $\mathrm{AlN}$ can be grown on a thin film, foil or plate of metal and polymer at low substrate temperatures. These composites were tried to be used for a microphone, loud- speaker, buzzer, earphone, and headphone. The sensitivity and the output were not enough for the practical applications. ${ }^{26), 43)}$

(e) Micro-actuator

Those composites described right above can be used as actuators. Actually, the composite loudspeaker, buzzer, earphone, and headphone are operated in the actuator mode of piezoelectric applications. Recently micro-actuators driven with piezoelectric thin films have been proposed and demonstrated. Ones are ultrasonic motors with sol-gel derived PZT films on silicon nitride membranes made by etching a small region of the Si substrate. Various types of actuator structures, almost as same as piezoelectric or ultrasonic motors which use bulk piezoelectric transducers, can be fabricated. ${ }^{44)}$ The others are meandering multiple cantilever beams made of $\mathrm{ZnO}$ films and $\mathrm{SiO}_{2}$ or other membranes fabricated by etching of a small region of Si substrates. ${ }^{45)}$

\subsection{Surface wave applications}

\section{(a) TV IF filters}

Surface acoustic wave television intermediate frequency filters made of piezoelectric $\mathrm{ZnO}$ thin films are now widely used. The overwhelmingly prevailing structure of the filters is of the type that has a half a wave length thick $\mathrm{ZnO}$ film sputter deposited covering a couple of interdigital electrodes on a glass substrate. ${ }^{26)}$ The sputter deposited $\mathrm{ZnO}$ film is of high quality and of high reliabilty and the production amount of the ZnO SAW TV IF filters has been steadily increasing and 3.7 million pieces of them were monthly produced in early months of 1991 .

(b) $\mathrm{GHz}$ filters

It has been known Sezawa mode propagating in the $\mathrm{ZnO}$ film epitaxially sputter-deposited on the $R$ plane sapphire substrate gives high velocity and high coupling. When the film thickness/wavelength ratio $h / \lambda$ of the fundamental Sezawa mode becomes low enough, its coupling coefficient becomes low and it gets cut-off. By choosing the $h / \lambda$ ratio for the fundamental Sezawa mode around 0.1, the coupling coefficient $k^{2}$ for the 3rd over-tone mode can be the maximum value of $4.7 \%$. The $1.86 \mathrm{GHz}$ surface acoustic wave filter made of the $\mathrm{ZnO}$ film epitaxially grown on the (1012) face of sapphire has been developed. By using the three transducer configuration for reducing the bidirectional loss of $3 \mathrm{~dB}$, and using split electrodes for the effective third overtone generation, the insertion loss has been decreased to less than $10 \mathrm{~dB}$. The propagation length is $550 \mu \mathrm{m}$ and the propagation loss is $70 \mathrm{~dB} / \mathrm{cm}$, which give the propagation loss of $3.9 \mathrm{~dB}$. The $1.05 \mu \mathrm{m}$ wide finger was fabricated by lift-off on the $\mathrm{ZnO}$ film. The frequency response is shown in Fig. 5. ${ }^{46)}$

The followings have been proposed and studied for many years and some of them have been used in small quantities.

(c) Nyquist filters,

(d) VHF wide-band long-time delay lines, 


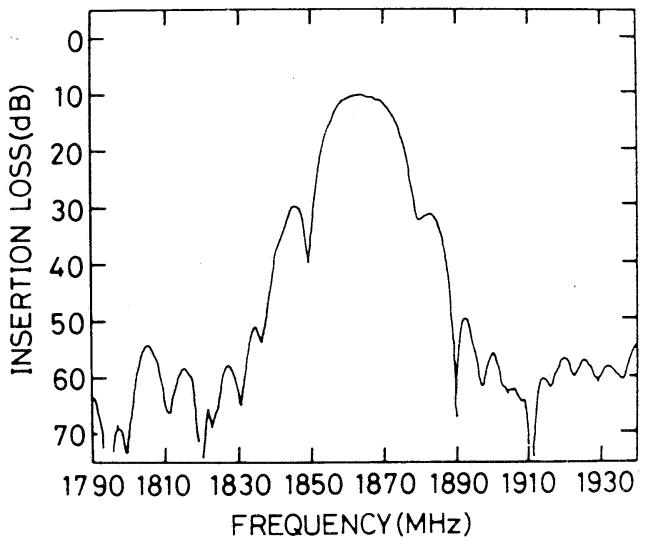

Fig. 5. The frequency response of the $1.86 \mathrm{GHz}$ filter using the surface layer wave, that is, the Sezawa wave.

(e) Convolver based signal processors,

(f) Acousto-optic devices,

(g) Ultrasonic amplifier.

\section{Optical grade piezoelectric film}

The forbidden band gap of oxides and nitrides are generally wide and may be transparent in visible region. However, their polycystlline films have considerable amount of absorption due to impurities and non stoichiometry, and also scattering at grain boundaries, substrate interface and film surface.

The $\mathrm{ZnO}, \mathrm{K}_{3} \mathrm{Li}_{2} \mathrm{Nb}_{5} \mathrm{O}_{15}$, PLZT and other films have been studied as optical waveguides. ${ }^{32)}$

The optical propagation loss in $\mathrm{ZnO}$ films grown on sapphire, $\mathrm{Si}$ and glass substrates has been improved to lower than $0.5 \mathrm{~dB} / \mathrm{cm}$. The minimum optical loss less than $0.1 \mathrm{~dB} / \mathrm{cm}$ was measured for one of the $\mathrm{ZnO}$ films on glass. Acousto-optic diffraction ratios of 95 and 98 percent for the $T E_{0}$ mode beam (at $632.8 \mathrm{~nm}$ ) were accomplished with the surface acoustic wave deflectors at acoustic powers of 90 $\mathrm{mW}$ in a $\mathrm{ZnO}$ film on glass and $80 \mathrm{~mW}$ in a $\mathrm{ZnO}$ film on $\mathrm{Si}$, respectively. ${ }^{47), 48)}$

Recently the integration of the SAW acousto-optic Bragg deflector of guided optical waves in the $\mathrm{ZnO}$ thin film on a Si substrate and Schottky diode photodetectors on the same $\mathrm{Si}$ substrate has been

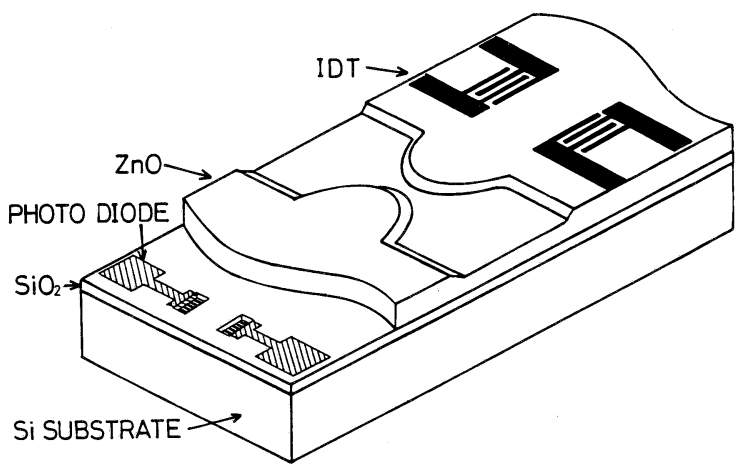

Fig. 6. The SAW-AO optical switch integrated on a Si substrate. The $\mathrm{ZnO}$ film is used as a piezoelectric transducer, optical wave guide, acousto-optic medium, and lens material. achieved as shown in Fig. 6.49) Thin film lens has been also integrated by making use of a gradual film thickness change, the refractive index dispersion of the fundamental mode on the film thickness. In addition, a fundamental mode pass filter has been integrated by making use of the mode cut-off property of the higher order modes in the area of the concave shaped convergent lens of the $\mathrm{ZnO}$ film. Thus guided optical waves SAW-Bragg deflected, mode selected and lens focused are detected by the Schottky diode photo-detector incorporated at the boundary between the $\mathrm{ZnO}$ film wave guide and the Si substrate. A couple of detectors are located one for deflected and the other for undeflected waves.

\section{Summaries}

Films of $\mathrm{ZnO}, \mathrm{AlN}, \mathrm{LiNbO}_{3}, \mathrm{Bi}_{12} \mathrm{PbO}_{19}, \mathrm{~K}_{3} \mathrm{Li}_{2} \mathrm{Nb}_{5} \mathrm{O}_{15}$, $\mathrm{PbTiO}_{3}, \mathrm{PZT}, \mathrm{Li}_{2} \mathrm{~B}_{4} \mathrm{O}_{7}$ and $\mathrm{Ta}_{2} \mathrm{O}_{5}$ have been fabricated mainly by rf magnetron sputtering. Among these films, the $\mathrm{ZnO}$ piezoelectric films have been widely put into practical uses.

The AlN films have been also studied along with $\mathrm{ZnO}$ films due to its higher ultrasonic velocity, higher electrical resistance and lower film growth temperature.

$C$-axis oriented $\mathrm{PbTiO}_{3}$ films are formed on patterned $\mathrm{Pt}$ electrode films imbedded on a $\mathrm{SrTiO}_{3}$ single crystal by a seeded lateral growth.

The Sezawa mode propagating in the $\mathrm{ZnO}$ film epitaxially sputter-deposited on the $R$ plane sapphire substrate gives a high velocity and high coupling.

Piezoelectric and ferroelectric materials are generally optically transparent and electrically insulating, and are useful for electro-, acousto-, and nonlinear optical devices. Then elements made of piezoelectric thin films can be integrated on a Si chip together with electrical integrated circuits.

\section{References}

1) N. F. Foster, IEEE Trans. on Sonics and Ultrason., SU-11, 63 (1964); also presented at the 1963 Ultrason. Symp. Washington, D.C., Dec. 4-6.

2) J. de Klerk and E. F. Kelly, Appl. Phys. Lett., 5, 2 (1964).

3) A. R. Hutson, Phys. Rev., 10, 505 (1960).

4) S. Wanuga, T. A. Midford and J. P. Dietz, presented at the 1965 Ultrason. Symp., Boston, Dec., 1965.

5) N. F. Foster and G. A. Rozgonyi, Appl. Phys. Lett., 8, 221 (1966).

6) T. M. Wauk and D. K. Winslow, Appl. Phys. Lett., 13, 286 (1968).

7) N. F. Foster, J. Appl. Phys., 40, 111 (1969).

8) T. Shiosaki, M. Ito, A. Kawabata and T. Tanaka, Jpn. J. Appl. Phys., 8, 407 (1969); ibid., 9, 631 (1970).

9) T. Mitsuyu, K. Wasa and S. Hayakawa, J. Appl. Phys., 47, 2901 (1976)

10) M. Adachi, T. Shiosaki and A. Kawabata, Ferroelectrics, 27, $89(1980)$

11) K. Iijima, R. Takayama, Y. Tomita and I. Ueda, J. Appl. Phys., 60, 2914 (1986).

12) K. Iijima, Y. Tomita, R. Takayama and I. Ueda, J. Appl. Phys., 60, 361 (1986).

13) A. Okada, J. Appl. Phys., 48, 2905 (1977).

14) R. Takayama, Y. Tomita K. Iijima and I. Ueda, J. Appl. 
Phys., 61, 411 (1987).

15) R. Takayama, T. Tomita, K. Iijima and I. Ueda, J. Appl. Phys., 63, 5868 (1988).

16) M. Adachi, T. Matsuzaki, T. Yamada, T. Shiosaki and A. Kawabata, Jpn. J. Appl. Phys., 26, 550 (1987).

17) A. Croteau, S. Matsubara, Y. Miyasaka and N. Shohata, Jpn. J. Appl. Phys., 26, Suppl. 26-2, 18 (1987).

18) K. Sreenivas and M. Sayer, J. Appl. Phys., 64, 1484 (1988).

19) R. Takayama and Y. Tomita, J. Appl. Phys., 65, 1966 (1989).

20) M. Okuyama and Y. Hamakawa, Ferroelectrics, 63, 243 (1985).

21) Y. Nakagawa, Y. Gomi and T. Okada, J. Appl. Phys., 61, 5012-17 (1987).

22) Y. Nakagawa, Proc. 16th EM Symp. (Tokyo, March 11, 1988) pp. 43-48 (in Japanese).

23) T. Uno, Proc. 8th Symp. on Ultrason. Electronics, Tokyo 1987; Jpn. J. Appl. Phys., 27, Suppl. 27-1, 120-22 (1988).

24) T. Shiosaki and A. Kawabata, Appl. Phys. Lett., 25, 10 (1974).

25) T. Shiosaki, Y. Yasumoto and A. Kawabata, J. Jpn. Soc. Appl. Phys., 44, Suppl., 115 (1975).

26) T. Shiosaki, Proc. IEEE Ultrason. Symp. (1978, IEEE New York) pp. 100-10.

27) T. Yamamoto, T. Shiosaki and A. Kawabata, J. Appl. Phys., 51, 3113 (1980)

28) T. Shiosaki and A. Kawabata, Ferroelectrics, 42, 219-32 (1982).

29) K. Tsubouchi and N. Mikoshiba, Proc. IEEE 1983 Ultrason. Symp. (IEEE, New York, 1983) pp. 299-311.

30) T. W. Grudkowski, J. F. Black, T. M. Reeder, D. E. Cullen and R. A. Wager, Appl. Phys. Lett., 37, 993 (1980).

31) K. M. Lakin and J. S. Wang, Appl. Phys. Lett., 38, 125 (1981).

32) H. Sato, H. Suzuki, C. Takahashi, C. Narahara and Y. Ebata, Proc. IEEE 1987 Ultrason. Symp. (IEEE, New York, 1987) pp. 363-68.

33) S. G. Burns, G. R. Kline and K. M. Lakin, Proc. IEEE 1987 Ultrason. Symp. (IEEE, New York, 1987) pp. 369-73.

34) G. R. Kline, R. S. Ketcham and K. M. Lakin, Proc. IEEE
1987 Ultrason. Symp. (IEEE, New York, 1987) pp. 375-80.

35) Y. Miyasaka, S. Hoshino and S. Takahashi, Proc. IEEE 1987 Ultrason. Symp. (IEEE, New York, 1987) pp. 385-93.

36) D. S. Bailey and J. B. Goodell, Proc. IEEE 1987 Ultrason. Symp. (IEEE, New York, 1987) pp.359-62.

37) D. Howell, L. Goddard and B. T. Khuri-Yakub, Proc. IEEE 1987 Ultrason. Symp. (IEEE, New York, 1987) pp. 381-83.

38) K. Kushida and H. Takeuchi, Appl. Phys. Lett., 50, 1800 (1987).

39) M. Okuyama, Y. Matsui, H. Seto and Y. Hamakawa, Jpn. J. Appl. Phys., 20, Suppl. 20-1, 315 (1981).

40) T. Fukami, T. Sakuma, K. Tokunaga and H. Tsuchiya, Jpn. J. Appl. Phys., 20, Suppl. 22-2, 18 (1983).

41) R. A. Moore, R. N. Sundeline, G. Borsuk, J. Lane, C. Huber and S. Lieberman, Proc. 1978 IEEE Ultrason. Symp. (IEEE, New York, 1978) p. 193.

42) V. Jipson and C. F. Quate, Appl. Phys. Lett., 32, 789 (1978).

43) T. Shiosaki, M. Hayashi and A. Kawabata, Proc. IEEE 1982 Ultrason. Symp. (IEEE New York, 1982) pp. 529-32.

44) A. M. Flynn, L. S. Tavrow, S. F. Bart, R. A. Brooks, D. J. Ehrlich, K. R. Udayakumar and L. E. Cross, Proc. IEEE 1990 Ultrason. Symp. (IEEE New York, 1990) pp.1163-72.

45) W. P. Robbins, D. L. Polla and D. E. Glumac, Proc. IEEE 1990 Ultrason. Symp. (IEEE New York, 1990) pp. 119195.

46) T. Kasanami, H. Ieki and J. Koike, Proc. 6th Meeting on Ferroelectric Materials and Their Applications, Kyoto 1987; Jpn. J. Appl. Phys., 26, Suppl. 26-2, 210-12 (1987).

47) M.-S. Wu, A. Azuma, T. Shiosaki and A. Kawabata, Appl. Phys. Lett., 62, 2482-84 (1987).

48) M.-S. Wu, A. Azuma, T. Shiosaki and A. Kawabata, Proc. IEEE 1987 Ultrason. Symp. (IEEE New York, 1987) pp. 529-33.

49) T. Shiosaki, N. Kitamura and A. Kawabata, to be published in the Proc. for the 7th International Symposium on Applications of Ferroelectrics, and also the Special Issue of Ferroelectrics for the 3rd International Symposium on Integrated Ferroelectrics.

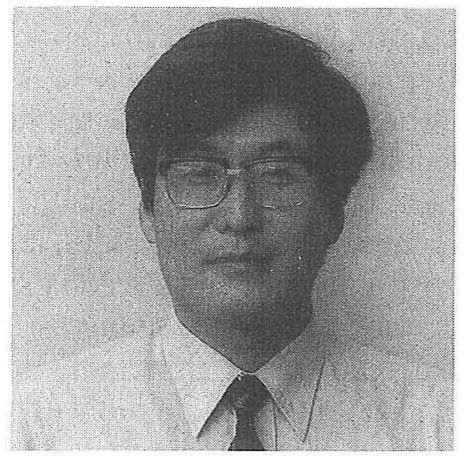

Tadashi SHIOSAKI was born in Osaka city, Japan, on March 13, 1944. He received the B.S, M.S, and Dr. degrees in Electronics from Kyoto University, Kyoto, Japan, in 1966, 1968, and 1973, respectively. In 1968, he joined the Faculty of Engineering, Kyoto University, where he was a Research Associate from 1968 to 1974. Since 1974 he has been an Associate Professor at the Department of Electronics, Kyoto University. He was a visiting Associate Professor at the EECS of the University of California, Berkeley, from 1978 to 1979. He has worked on piezoelectric, pyroelectric, ferroelectric and acousto- and nonlinear-optic materials and their applications.

Dr. Shiosaki is a member of the nine major academic societies and institutes related to his research activities in Japan and USA. He is the current chairman of the Research Committee on Dielectrics in Japan Technology Transfer Association and the Special Committee on Electronic Ceramics in Japan Electronic Industry Development Association. 